\title{
LA-ICP-MS quantitative imaging of multi-mineral assemblages: analytical set-up and algorithm for data processing
}

\author{
L.V. DANYUSHEVSKY ${ }^{1,2^{*}}$, C. A. NORRIS ${ }^{3}$
}

${ }^{1}$ TMVC Research Hub, University of Tasmania, Hobart, TAS 7005, Australia (*correspondence: 1.dan@utas.edu.au) ${ }^{2}$ CODES and Earth Sciences, University of Tasmania, Hobart, TAS 7005, Australia

${ }^{3}$ Norris Scientific, Hobart, Australia (an@norsci.com)

LA-ICP-MS is now widely used for imaging of elemental and isotope ratio variations in a wide range of natural and synthetic materials $[1,2,3,4]$. Multi-mineral geological samples are one of the more challenging types of material to characterise by this technique [4] as different minerals exhibit different ablation yields and often contain major elements that cannot be quantified by ICP-MS (e.g., C, O, F). Accurate quantification of such images requires that different mineral phases present within the imaged area are identified and that separate quantification algorithms are applied to pixels corresponding to different mineral phases [5].

We present an approach to algorithm development for quantification of multi-matrix images, and its implementation in LADR data reduction software [6]. The current implementation of mineral identification involves an interactive assessment of elemental distributions across the imaged area, with the user being able to use different elemental combinations to determine the number of minerals present in the image and their types, and also to identify areas within the image corresponding to each of the mineral phases present. The data reduction algorithm then assigns the defined mineral type to each pixel, which is then quantified using the appropriate quantification scheme, providing that all necessary reference materials have been analysed during the analytical session to enable all of the quantification schemes required.

[1] Woodhead et al. (2007) Geostand. Geoanal. Res. 31, 331-343.

[2] Evans \& Muller (2013) J. Anal. At. Spectrom. 28, 1039-1044

[3] Van Malderen et al. (2017) Anal. Chem. 89, 4161-4168. [4]

Gundlach-Graham et al. (2018) Geostand. Geoanal. Res. 42, 559-

574. [5] Paul et al. (2012) J. Anal. At. Spectrom. 27(4), 700-706.

[6] https://norsci.com/ladr/ 